\title{
Optimization of Ostrich Eggshell Catalyst in Transesterification Using Waste Cooking Oil via Response Surface Methodology
}

\author{
Yie Hua Tan ${ }^{1, a^{*}}$, Mohammad Omar Abdullah ${ }^{\mathrm{b}}$, Jibrail Kansedo ${ }^{\mathrm{a}}$, Agus Saptoro ${ }^{\mathrm{a}}$ and Cirilo \\ Nolasco Hipolito ${ }^{\mathrm{c}}$ \\ ${ }^{a}$ Department of Chemical Engineering, Curtin University Malaysia, CDT 250, 98009 Miri, \\ Sarawak, Malaysia. \\ ${ }^{b}$ Department of Chemical Engineering and Energy Sustainability, Faculty of Engineering, \\ Universiti Malaysia Sarawak, 94300 Kota Samarahan, Malaysia. \\ ${ }^{c}$ Instituto of Biotechnology. Universidad del Papaloapan. Circuito Central \#200, Col. Parque \\ Industrial, CP. 68301. Tuxtepec, Oaxaca. Mexico.
}

\begin{abstract}
In this research work, waste cooking oil biodiesel production was optimized using a design of experiment (DOE) approach: response surface methodology (RSM), based on a five level, three variables central composite design (CCD) to investigate the interaction effects of the different combination of transesterification reaction variables such as catalyst concentration, reaction temperature and time, using ostrich eggshell $\mathrm{CaO}$ base catalyst. A quadratic polynomial equation of the response, biodiesel yield was attained via multiple regression analysis to predict the relation between yield and the chosen variables. The results showed that the temperature and time are the most important process parameters on the biodiesel production. The optimal operating conditions for the transesterification reaction have been found to be: reaction temperature of $67{ }^{\circ} \mathrm{C}$, alcohol/oil molar ratio of 10:1 (fixed parameter), catalyst concentration of $1.97 \% \mathrm{w} / \mathrm{w}$ and reaction time of $1.77 \mathrm{~h}$. The predicted biodiesel yield was about $99.67 \%$ under the optimal conditions through the ANOVA numerical method.
\end{abstract}

Keywords: Biodiesel production, Heterogeneous catalyst, Ostrich eggshell, Optimization, RSM.

\section{Introduction}

The tremendous growth of world population would eventually result in the increasing the worldwide energy demand. The primary power sources are mainly fossil fuel based, such as natural gas, crude oil and coal. In order to cater the increasing energy demand issue along with the environmental and socio-economic concerns, the findings of new alternative and renewable energy sources are called worldwide. There are various types of renewable energy, including wood, biomass, hydro water, underground geothermal, solar, tidal, wind, waves and biofuels (biodiesel and bioethanol) [1]. Biodiesel is the one of the most promising biofuels synthesized from the renewable resources, especially plant derived materials. It can be categorized into processing vegetable oils (e.g., soya bean, rapeseed, peanut, sunflower, coconut, corn, palm oil, etc.) and after post processing vegetable oil, which is waste cooking oil [2]. Chemically, biodiesel is defined as the long-chain alkyl esters (monoalkyl esters of long-chain fatty acids like lauric, palmitic, stearic, oleic, etc.) derived from

\footnotetext{
* Corresponding author. Tel.: +085-442434

E-mail address: tanyiehua@curtin.edu.my
}

Manuscript History:

Received 19 June, 2018, Revised 18 September, 2018, Accepted 26 September, 2018, Published 30 September, 2018

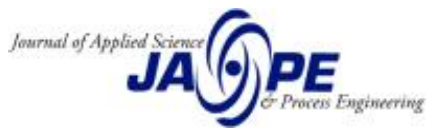


renewable biological resources such as vegetable oils or animal fats via a transesterification reaction [3]. Biodiesel has low toxicity, biodegradability, high-lubricity, high Cetane number, higher flash point, high oxygen content which result in good combustion efficiency and does not contain sulphur and aromatic compounds [4]. The transesterification process involves the alcoholysis reaction between the oil feedstock and alcohol with the presence of catalyst, to obtain methyl esters (biodiesel) and glycerin (soap, side product) [5].

The transesterification process is influenced by a several operating parameters, such as the type of the oil feedstock and alcohol, catalyst loading, alcohol to oil molar ratio, reaction temperature, reaction time and agitation speed are the main variables which will be affecting the biodiesel yield. Thus, optimization of biodiesel production is of utmost importance as process exploration and optimization are often laborious and time-consuming. These are requiring patience and commitment especially in the repeated experiments.

Therefore, current paper will be discussing the findings of the experiments carried out to optimize the biodiesel production process via heterogeneous base catalyzed transesterification. This paper is focusing on the three important operating parameters which is reaction time, reaction temperature and catalyst loading that will influence the conversion of FFAs (free fatty acid) from waste cooking oil in a two steps transesterification reaction with methanol using ostrich eggshellderived $\mathrm{CaO}$ base catalyst. The main objectives were to develop a method that explain the relationships or interaction effects between the variables (reaction time, reaction temperature and concentration of catalyst) and the response (biodiesel yield); and to optimize the operating process conditions for biodiesel production using central composite design (CCD) via response surface methodology (RSM).

Response surface methodology (RSM) is a combination of statistical and mathematical techniques especially for empirical modelling, problem analysis development, modification and optimization of various processes to obtain an optimal response [6].

\section{Procedure}

\subsection{Materials}

Waste cooking oil was given by a local restaurant in Kuching, Sarawak which contained 0.60 wt $\%$ of water with an acid value of $1.24 \mathrm{mg} \mathrm{KOH} / \mathrm{g}$ and a saponification value of $214 \mathrm{mg} \mathrm{KOH} / \mathrm{g}$. Its density at room temperature is $0.98 \mathrm{~g} / \mathrm{cm}^{3}$. The waste cooking oil was first filtered and heated inside the conventional oven up to $100{ }^{\circ} \mathrm{C}$ to eliminate the dirt and moisture before used as the oil feedstock for the transesterification reaction. Ostrich-eggshells were provided from the local ostrich farm in Sibu, Sarawak. The eggshells were first cleaned and washed with distilled water. The inner membrane layers of the eggshell were removed manually to eliminate the undesirable impurities. The heterogeneous $\mathrm{CaO}$ catalyst was prepared by crushing and then grounding the eggshells to powder form using crusher and grinder. Then, these eggshell powders were calcined at $1000{ }^{\circ} \mathrm{C}$ for 4 hours in muffle furnace to convert the calcium carbonate compound to calcium oxide and release carbon dioxide gas.

\subsection{Transesterification Reaction}

The free fatty acids (FFA) content of the waste cooking oil was firstly reduced using sulphuric acid, $\mathrm{H}_{2} \mathrm{SO}_{4}$ through acid esterification process. Methanol, $\mathrm{H}_{2} \mathrm{SO}_{4}$ and the oil were blended in a beaker and heated up to $65{ }^{\circ} \mathrm{C}$ for 1 hour by magnetic stirrer and heating mantle. The mixture was then allowed to settle for another one hour and the methanol- water fraction was removed in a separating funnel. Next, the heterogeneous base catalyst was activated by mixing the ostrich eggshell-derived $\mathrm{CaO}$ base catalyst and methanol in a closed cap bottle. It was stirred at $65^{\circ} \mathrm{C}$ with a speed of $120 \mathrm{rpm}$ 
for one to two hours by incubated orbital shaker. Thereafter, an appropriate amount of oil was added into the mixture and transesterification reaction was carried out. Fixed methanol/oil molar ratios, i.e. 10:1 and different catalyst loading (wt $\%$ based on the oil weight), reaction temperature and time were selectively chosen to manipulate the transesterification reaction. Upon the completion of transesterification reaction, the mixture of the product was centrifuged at $3000 \mathrm{rpm}$ for $20 \mathrm{mins}$. The lower layer of glycerin and $\mathrm{CaO}$ catalyst were carefully removed and weighed while the upper methyl ester layer was washed several times with hot deionized water. This procedure was repeated until the $\mathrm{pH}$ value in the upper aqueous phase reached 7.0. The obtained biodiesel was heated over $100{ }^{\circ} \mathrm{C}$ in oven to remove the excessive water and methanol. The biodiesel yield was calculated using the following formula:

$$
\text { Biodiesel yield }=[\mathrm{W}(\text { biodiesel }) \div \mathrm{W}(\text { waste cooking oil })] \times 100 \%
$$

whereas, $\mathrm{W}$ (biodiesel) and $\mathrm{W}$ (waste cooking oil) are the weight of biodiesel and weight of waste cooking oil, respectively.

\subsection{Optimization}

A five-level-three-factor central composite design (CCD) was employed to optimize the operating variables (reaction temperature, catalyst loading and reaction time) to achieve high value of biodiesel yield. Assume the CCD design is a sphere around the factorial cube, 20 experimental runs $\left(2 k+2 * k+n_{\mathrm{c}}\right)$, have $k$ factors, then $2 k$ factorial points $=8,2 * k$ axial points $=6$ and $n_{\mathrm{c}}$ replicated center points $=6$ were performed in a randomized order. Here, $k$ is the number of independent variables and $k=3$ shall provide sufficient information to allow a full second-order polynomial model [7]. The fourth root of the number of points in the factorial part of the design, gives us a rotatable design, whereas the axial point is defined as $\alpha=1.68$, through $\alpha=\left[2^{\mathrm{k}}\right]^{1 / 4}$, whereas, $\mathrm{k}=3$ in this research. The range and levels of individual variables of $3^{\mathrm{k}}$ design were given in Table 1 . The experiment design was given in Table 2 . The value of biodiesel yield is the response.

The obtained experimental data was further analyzed by the response surface regression method using the following second-order polynomial formula:

$$
Y=\beta_{0}+\sum_{i=1}^{n} \beta_{i} x_{i}+\sum_{i=1}^{n} \beta_{i i} x_{i}^{2}+\sum_{i=1}^{n} \sum_{j=1}^{i-1} \beta_{i j} x_{i} x_{j}+\varepsilon_{i}
$$

Where response variable of interest is $Y$ (biodiesel yield), $\beta_{\mathrm{i}}$ and $\beta_{\mathrm{ij}}$ are coefficients coded from the results of regression, a set of predictor variables $\mathrm{x}_{1}, \mathrm{x}_{2}, \mathrm{x}_{3} \ldots$ on the response. While, $\mathrm{n}$ is the number of independent parameters $(\mathrm{n}=3)$ and $\varepsilon$ represents the error in the system [8]. The analysis was performed using Design-Expert 10.0 software and the respective coefficients were interpreted using F-test or p-value. Analysis of variance (ANOVA), regression analysis and graphical analysis were used to optimize the operating parameters in order to achieve maximum yield of biodiesel. 
Table 1. Codes, ranges and levels of different independent variables in RSM design

\begin{tabular}{|c|c|c|c|c|c|}
\hline Independent variables & Units & $\mathbf{- 1}$ & $\mathbf{1}$ & $\boldsymbol{- \alpha}$ & $+\boldsymbol{\alpha}$ \\
\hline Catalyst loading & $\% \mathrm{w} / \mathrm{v}$ & 1 & 2 & 0.66 & 2.34 \\
\hline Temperature & ${ }^{\circ} \mathrm{C}$ & 50 & 80 & 39.77 & 90.23 \\
\hline Time & $\mathrm{hr}$ & 1 & 2 & 0.66 & 2.34 \\
\hline
\end{tabular}

Table 2. Experimental data for the yield of biodiesel obtained from the a five-level-three-factor CCD for RSM

\begin{tabular}{|c|c|c|c|c|c|}
\hline & & Factor 1 & Factor 2 & Factor 3 & Response 1 \\
\hline Run & Space Type & A:Catalyst loading & B:T & C:Time & Biodiesel yield \\
\hline & & $\% \mathrm{w} / \mathrm{v}$ & ${ }^{\circ} \mathbf{C}$ & hr & $\%$ \\
\hline 1 & Center & 1.5 & 65.0 & 1.5 & 95.6 \\
\hline 2 & Factorial & 2.0 & 80.0 & 2.0 & 90.8 \\
\hline 3 & Factorial & 1.0 & 80.0 & 2.0 & 88.3 \\
\hline 4 & Axial & 1.5 & 65.0 & 2.3 & 89.3 \\
\hline 5 & Factorial & 1.0 & 50.0 & 2.0 & 82.0 \\
\hline 6 & Factorial & 1.0 & 50.0 & 1.0 & 65.8 \\
\hline 7 & Factorial & 2.0 & 50.0 & 1.0 & 75.6 \\
\hline 8 & Axial & 1.5 & 65.0 & 0.7 & 64.8 \\
\hline 9 & Axial & 2.3 & 65.0 & 1.5 & 93.9 \\
\hline 10 & Factorial & 2.0 & 50.0 & 2.0 & 89.3 \\
\hline 11 & Center & 1.5 & 65.0 & 1.5 & 96.5 \\
\hline 12 & $\overline{\text { Axial }}$ & 1.5 & 39.8 & 1.5 & 50.8 \\
\hline 13 & Center & 1.5 & 65.0 & 1.5 & 97.3 \\
\hline 14 & Axial & 0.7 & 65.0 & 1.5 & 76.7 \\
\hline 15 & Center & 1.5 & 65.0 & 1.5 & 96.7 \\
\hline 16 & Center & 1.5 & 65.0 & 1.5 & 97.5 \\
\hline 17 & Axial & 1.5 & 90.2 & 1.5 & 82.1 \\
\hline 18 & Center & 1.5 & 65.0 & 1.5 & 95.6 \\
\hline 19 & Factorial & 1.0 & 80.0 & 1.0 & 78.8 \\
\hline 20 & Factorial & 2.0 & 80.0 & 1.0 & 80.8 \\
\hline
\end{tabular}




\section{Results and Discussion}

\subsection{RSM Analysis}

The gotten experimental biodiesel yields were used to obtain a regression model. The predicted values of biodiesel yield were calculated using the regression model in Design-Expert software developed a 23 factorial CCD resulting in 20 runs with six axial points and six replicates. Based on the obtained coded parameters, the predicted quadratic regression model with defined coefficients was given by the following equation:

Biodiesel yield $=96.33+3.71 * \mathrm{~A}+5.77 * \mathrm{~B}+6.62 * \mathrm{C}-1.57 * \mathrm{AB}-0.24 * \mathrm{AC}-1.30 * \mathrm{BC}-2.62 * \mathrm{~A}^{2}-9.28 * \mathrm{~B}^{2}-$ $5.54 * \mathrm{C}^{2}$

where $\mathrm{A}, \mathrm{B}$ and $\mathrm{C}$ are the coded forms of catalyst loading, reaction temperature and time, respectively. While, $\mathrm{AB}, \mathrm{AC}$, and $\mathrm{BC}$ are the interaction terms among the variables whereas $\mathrm{A}^{2}, \mathrm{~B}^{2}$ and $\mathrm{C}^{2}$ are the squared terms of the variables. Table 3 shows the results of Analysis of variance (ANOVA) for the predicted values fit well with the experimental values. The R-square value of the coefficient of multiple determination $\left(\mathrm{R}^{2}=0.9106\right)$ revealed that the model best fits the experimental data. The linear, quadratic and combined effects of the independent parameters were included to define their effects on the biodiesel yield. The significance level of each parameter which was evaluated by the probability value ( $\mathrm{p}$-value) as per listed in Table 3. At 95\% confidence level, the pvalues less than 0.05 indicated the significant effects of those parameters. As shown in Table 3, it can be found that the most significant variable on the biodiesel yield were arranged in ascending order, i.e. the quadratic terms of reaction temperature, $B^{2}(p<0.0001)$, time, $C^{2}(p=0.0026)$ and catalyst loading, $\mathrm{A}^{2}(\mathrm{p}=0.0894)$ and followed by linear term of time, $\mathrm{C}(\mathrm{p}=0.0009)$, temperature, $\mathrm{B}(\mathrm{p}=$ $0.0024)$ and catalyst loading, $A(p=0.027)$. While the $p$-value for the rest interactive effects are larger than 0.1. Cor Total shows the amount of variation around the mean of the observations. The corrected total sum of squares (adjusted for the mean) is useful as a check sum on the calculations. It does come into play for statistics such as R-squared. The value of sum of square of Cor Total is 3132, that's mean the generated model is close the data are to the fitted regression line. In contrary, the p-value of the Lack of Fit is less than 0.0001 , i.e. significant, this may due to the small sample size in the experimental design and some points were located beyond the upper and lower limits. As using a small sample the assumptions of parametric tests may be violated and may not be sufficiently powered to detect a difference between the factors. 
Table 3. ANOVA for biodiesel model

\begin{tabular}{|c|c|c|c|c|c|}
\hline & Sum of & & Mean & $\mathbf{F}$ & p-value \\
\hline Source & Squares & df & Square & Value & Prob $>$ F \\
\hline Model & 2851.96 & 9 & 316.88 & 11.31 & 0.0004 \\
\hline A-Catalyst loading & 187.88 & 1 & 187.88 & 6.71 & 0.027 \\
\hline B-Temperature & 454.22 & 1 & 454.22 & 16.21 & 0.0024 \\
\hline C-Time & 598.85 & 1 & 598.85 & 21.38 & 0.0009 \\
\hline $\mathrm{AB}$ & 19.69 & 1 & 19.69 & 0.7 & 0.4215 \\
\hline $\mathrm{AC}$ & 0.47 & 1 & 0.47 & 0.017 & 0.9 \\
\hline $\mathrm{BC}$ & 13.49 & 1 & 13.49 & 0.48 & 0.5035 \\
\hline $\mathrm{A}^{2}$ & 99.14 & 1 & 99.14 & 3.54 & 0.0894 \\
\hline $\mathrm{B}^{2}$ & 1242.1 & 1 & 1242.1 & 44.33 & $<0.0001$ \\
\hline $\mathrm{C}^{2}$ & 443.1 & 1 & 443.1 & 15.82 & 0.0026 \\
\hline Residual & 280.16 & 10 & 28.02 & & \\
\hline Lack of Fit & 276.84 & 5 & 103.37 & 33.23 & $<0.0001$ \\
\hline Pure Error & 3.33 & 5 & 0.67 & & \\
\hline Cor Total & 3132.12 & 19 & & & \\
\hline
\end{tabular}

$\mathrm{R}^{2}$ 0.9106; adjusted $\mathrm{R}^{2} 0.83$.

\subsection{Response Surface Analysis}

The full three-dimensional (3D) reciprocal space map (RSM) graphs are the graphical measurement technique which can articulate the optimal values of each variable [9]. Three different 3D RSM surface contour plots, Figure 1(a)-(c) are illustrated to show the interaction effect of catalyst loading, reaction time and temperature on biodiesel yield.

From the Figure 1(a)-(c), increasing in biodiesel yield was observed with the increase of catalyst concentration, reaction temperature and time at first, but the trend was reversed when the respective parameters reached a certain value, i.e. the optimum value. The Figure 1(c) shows that the reaction time and catalyst concentration were insignificant on the biodiesel yield. In this study, temperature was defined as the key parameter, which will speed up the rate of reaction, that is resulting in higher biodiesel yield. With increasing reaction temperature, yield of biodiesel increased exponentially to the boiling point of methanol. At low temperature, lower yield was noticed due to the subcritical state of methanol. At higher temperature (greater than boiling point of methanol), the methanol evaporated and reduced the overall biodiesel yield [10]. Yield of biodiesel decreased when the concentration of heterogeneous $\mathrm{CaO}$ ostrich catalyst increased more than $1.5 \% \mathrm{w} / \mathrm{v}$ as shown in Figure 1(b) and (c). Glycerol was formed rapidly when the catalyst loading is increased and thus lower the formation of biodiesel [11]. Lastly, the interaction effects of reaction time and catalyst concentration is shown in Figure 1(c). This showed that the effect of catalyst concentration with time is insignificant and the value of this interaction coefficient ( $p>0.05$ ) in table 3 has supported this fact. 


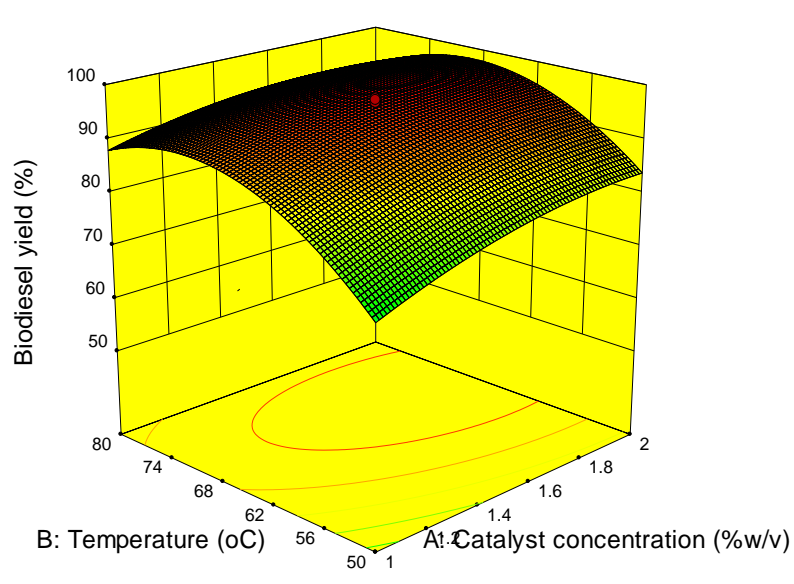

(a)

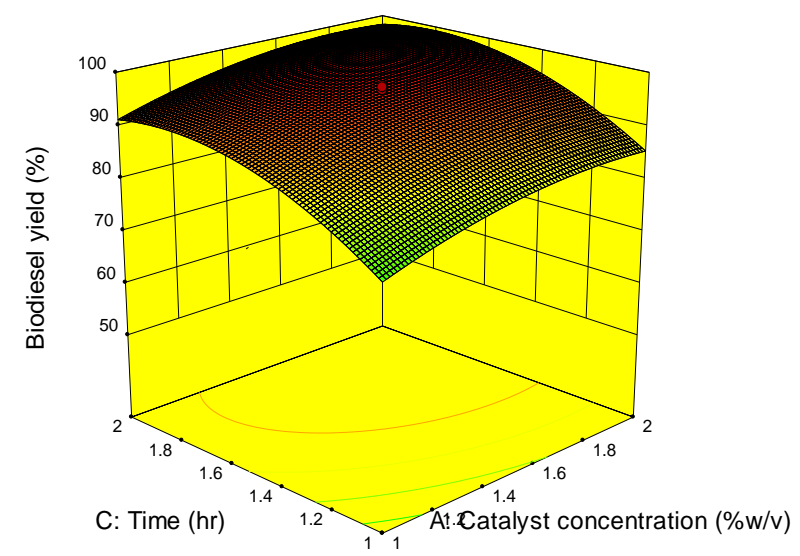

(c)

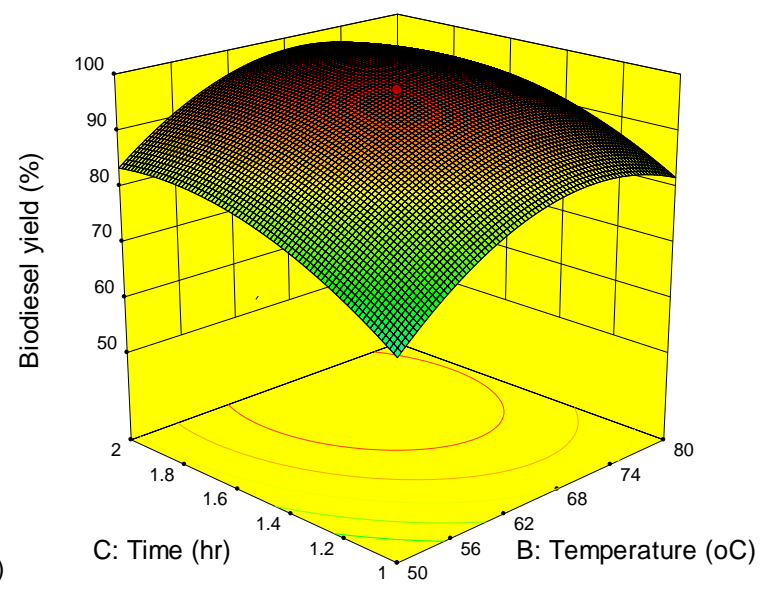

(b)

Figure 1.3D plot of the combined effects of (a), catalyst concentration and temperature (b) time and temperature (c) time and catalyst concentration on the biodiesel yield.

\subsection{Optimization of Transesterification}

The numerical method of the regression model was employed using Design-Expert 10.0 software to optimize the operating condition for the transesterification. The result was shown as in Figure 2. Experimental validation demonstrated a biodiesel yield of $94 \%$. The small discrepancy of \pm $5 \%$ between predicted and validated yield suggests that RSM was a suitable tool in optimizing the proposed operating conditions for biodiesel production. 


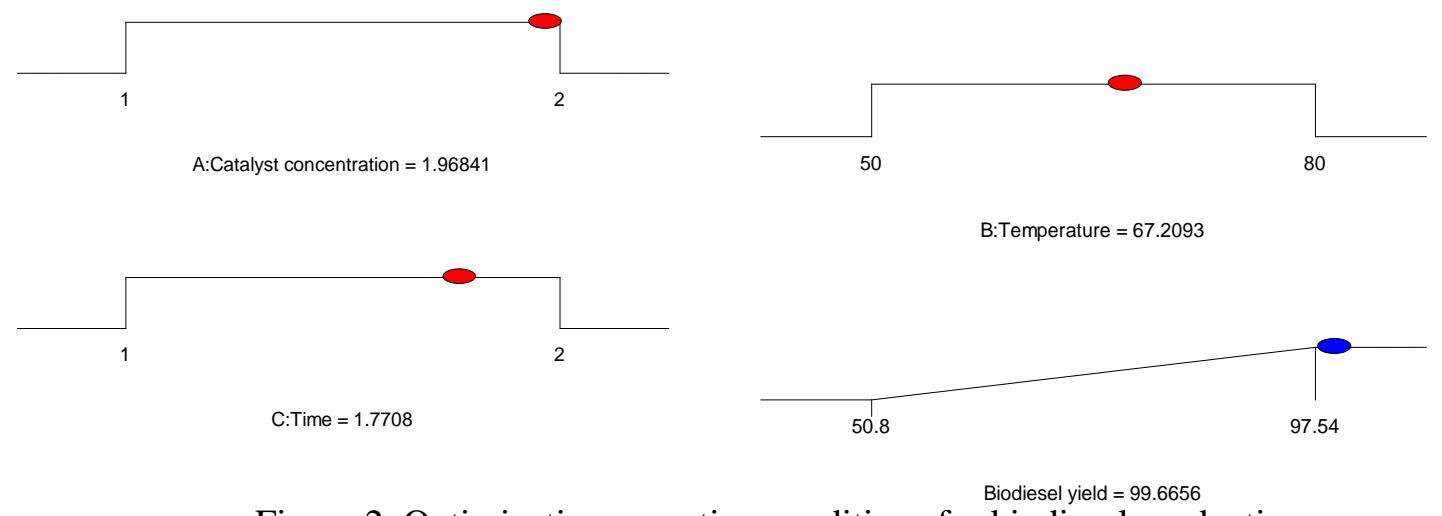

Figure 2. Optimization operating conditions for biodiesel production.

\section{Conclusion}

Response surface methodology was successfully applied to study the relationship of catalyst loading, temperature and time variables on the transesterification process from waste cooking oil. RSM proved to be a powerful tool for the optimization of biodiesel production at a fixed methanol to oil molar ratio. A second-order model was developed to describe the interaction effects between biodiesel yield and the main parameters, i.e. catalyst loading, reaction temperature and time. The ANOVA's result implied that temperature was the most significant factor affecting the biodiesel yield among the selected variables. In order to minimize the biodiesel production cost, optimization of the independent parameters was performed. Numerical function in RSM gave the optimum operating conditions of $1.97 \%$ w/v catalyst loading, 1.77 hours and $67{ }^{\circ} \mathrm{C}$. Maximum yield of biodiesel, $99.67 \%$ was achieved at the optimum operating conditions.

\section{Acknowledgements}

The authors gratefully acknowledge the support from Curtin University Malaysia and University Malaysia Sarawak. This research was supported by the FRGS Grant Scheme, Contract No: FRGS/1/2016/TK07/UNIMAS/01/2 and Code No. F02/FRGS/1490/2016 granted financial resource from Ministry of Education, Malaysia. We thank our colleagues who provided insight and expertise that greatly assisted the research.

\section{References}

[1] Leung, D.Y.C., Wu, X. and Leung, M.K.H. (2011). A Review on Biodiesel Production Using Catalyzed Transesterification, Appl. Energy, Vol. 87, No. 4, 1083-1095.

[2] Uzun, B.B., Kılıc, M., Özbay, N., Pütün, A.E. and Pütün, E. (2012). Biodiesel Production from Waste Frying Oils: Optimization of Reaction Parameters and Determination of Fuel Properties, Energy, Vol. 44, 347-351.

[3] Azocar, L., Ciudad, G., Heipieper H. and Navia, R. (2010). Biotechnological Processes for Biodiesel Production Using Alternative Oils, Appl Microbiol Biotechnol, Vol. 88, 621-636.

[4] Chakraborty, R. and Banerjee, S.B.A. (2011). Application of Calcined Waste Fish (Labeo Rohita) Scale as Low-Cost Heterogeneous Catalyst for Biodiesel Synthesis, Bioresour Technol, Vol. 102, 3610-3618.

[5] Tang, Y., Xu, J., Zhang, J., Lu, Y. (2013). Biodiesel Production from Vegetable Oil by Using Modified CaO as Solid Basic Catalysts, J Clean Prod, Vol. 42, 198-203.

[6] Agrawal, S., Singh, B. and Sharma, Y.C. (2012). Exoskeleton of a Mollusk (Pila globosa) as a Heterogeneous Catalyst for Synthesis of Biodiesel Using Used Frying Oil, Ind Eng Chem Res, Vol. 51, 11875-11880. 
[7] Lesbani, A., Susi, Y., Verawaty, M. and Mohadi, R. (2015). Calcium Oxide Decomposed from Chicken's and Goat's Bones as Catalyst for Converting Discarded Cooking Oil to be Biodiesel, Aceh Int. J. Sci. Technol., Vol. 4, 7 - 13.

[8] Roschat, W., Siritanon, T., Yoosuk, B., Promarak, V. (2016). Biodiesel Production from Palm Oil Using Hydrated Lime-Derived $\mathrm{CaO}$ as a Low-Cost Basic Heterogeneous Catalyst, Energy Convers Manage, Vol. $108,459-467$.

[9] Yoosuk, B., Udomsap, P., Puttasawat, B., Krasae, P. (2010). Improving transesterification activity of CaO with hydration technique, Bioresour Technol, Vol. 101,3784-3786.

[10] Tan, Y.H., Abdullah, M.O., Nolasco-Hipolito, C. and Zauzi, N.S.A. (2017). Application of RSM and Taguchi Methods for Optimizing the Transesterification of Waste Cooking Oil Catalyzed by Solid Ostrich and Chicken-Eggshell Derived CaO, Renew. Energy, Vol. 114, No. B,437-447.

[11] Suryaputra, W., Winata, I., Indraswati, N. and Ismadji, S. (2013). Waste Capiz (Amusium cristatum) Shell as a New Heterogeneous Catalyst for Biodiesel Production, Renew. Energy, Vol. 50, 795-799. 